\title{
Determinants of Mortality in Children under Five Years of Age with Severe Acute Malnutrition Admitted to the Yalgado Ouédraogo Teaching Hospital (Burkina Faso)
}

\author{
Zoubga W. Adama ${ }^{1, *}$, Compaoré W.R. Ella ${ }^{1}$, Marcel D. Bengaly ${ }^{1}$, Zan Angèle ${ }^{2}$, Pietra \\ Virginio $^{3}$, Kam K. Ludovic ${ }^{2}$ and Traoré S. Alfred ${ }^{1}$
}

${ }^{1}$ Biological, Food and Nutritional Sciences Research Centre (CRSBAN), UFR-SVT, Department of Microbiology, University of Ouagadougou, Ouagadougou, Burkina Faso

${ }^{2}$ Centre Hospitalier Universitaire, Yalgado Ouedraogo, Ouagadougou, Burkina Faso

${ }^{3}$ Public Health and Infectious Diseases, Brescia, Italy

\begin{abstract}
Background: To determine critical factors associated with severely malnourished children under five this casecontrol study was conducted.

Methods: The data of a total of 433 children aged 0-59 months and admitted to the Hospital Yalgado Ouedraogo, (CHU - YO) between January 31, 2009 to January 31, 2013, were included in the analysis: 72 for the case group and 361 for the control group. Clinical and treatment records were accessed and data were analyzed.

Results: For clinical signs, determinants of mortality were diarrhea $[\mathrm{OR}=4.6 ;(95 \% \mathrm{Cl} 2.6-8.2]$, anorexia $[\mathrm{OR}=2.7$; $(95 \% \mathrm{Cl} 1.4-5.0]$ and hepatomegaly $[\mathrm{OR}=2.6 ;(95 \% \mathrm{Cl} 1.4-4.8]$. For infections, determinants of mortality were pediatric HIV/AIDS [OR $=10.9 ;(95 \% \mathrm{Cl} 5.6-21.5]$ and digestive illnesses [OR $=5.1(95 \% \mathrm{Cl} 2.8-9.4)]$. Regarding the complications of malnutrition, determinants of mortality were severe dehydration [OR $=16.4(95 \% \mathrm{Cl} 8.0-33.5)]$, skin lesions [OR $=14.3$ $(95 \% \mathrm{Cl} 6.4-31.9)]$, heart failure $[\mathrm{OR}=6.8(95 \% \mathrm{Cl} 2.5-19.0)]$ and severe anemia $[\mathrm{OR}=3.2(95 \% \mathrm{Cl} 1.4-7.1)]$. For biochemical indicators, low serum sodium $[\mathrm{OR}=0.7(95 \% \mathrm{Cl} 0.5-1.0)]$ and potassium levels $[\mathrm{OR}=0.9(95 \% \mathrm{Cl} 0.9-1.0)]$ were the critical factors. In addition the risk of death was associated with low value of MUAC [OR $=0.9(95 \% \mathrm{Cl} 0.8-$ 0.9)].

Conclusions: The risk of death of children with severe acute malnutrition varies according to different factors studied.
\end{abstract}

Keywords: Severe acute malnutrition, determinants of mortality, under-five children.

\section{BACKGROUND}

According to estimates of the World Health Organization (WHO) in 2012, 162 million children under 5 years still suffer from chronic malnutrition, 99 million from underweight and 51 million from acute malnutrition including 17 million in the severe form worldwide [1]. In developing countries, including many African countries, maternal and child malnutrition is the underlying cause of more than a third ( 3.5 million) of all deaths in children under 5 years [2]. Burkina Faso as the rest of sub-Saharan Africa also faces the challenges of malnutrition.

In 2012, according to estimates by the World Food Program (WFP) and the general direction for the promotion of rural economy (DGPER), nearly half of low-income households in Burkina Faso were victims of food insecurity that affected their nutritional situation [3]. The national nutritional survey conducted by the

*Address correspondence to this author at the Biological, Food and Nutritional Sciences Research Centre (CRSBAN), UFR-SVT, Department of Microbiology, University of Ouagadougou, Ouagadougou, Burkina Faso

Tel: +226 78811240; E-mail: zoubgawa12@yahoo.fr
Direction of Nutrition (DN) in 2012 showed that $10.9 \%$ of 0-5 years-old children were acutely malnourished (including $1.8 \%$ with severe acute malnutrition), $32.9 \%$ underweight $(10.5 \%$ with severe underweight) and $24.4 \%$ chronically malnourished $(6.2 \%$ with the severe form) [4].

Malnutrition is an underlying cause of child mortality in Burkina Faso. Mortality rates in the public health system of Burkina Faso, as a result of malnutrition, remain high and raise some concerns. According to the estimates of the General Direction of Health Information and Statistics [5] the death rate was 19.8\% among hospitalized children presenting severe acute malnutrition (SAM) with edema and $2.9 \%$ for those with SAM and without edema at the Teaching hospital of Yalgado Ouedraogo (CHU-YO) in the capital city Ouagadougou Similarly, the death rate for the same groups of children was $16.0 \%$ and $12.6 \%$, respectively, at the Teaching hospital of Souro Sanou in the second biggest town of the country [5]. Nationally, the malnutrition-related mortality was $13.5 \%$ for the SAM with edema and $8.1 \%$ for SAM without edema when pooling data from the teaching and regional hospitals together [5]. These rates are similar to what was 
reported in Cameroun and Guinea $(20 \%$ and $14 \%$ respectively) $[6,7]$. However, according to the WHO norms, rates of death between $11-20 \%$ are considered unacceptable [8].

Although the association between malnutrition and all-cause mortality is well established, the relationship between malnutrition and mortality attributed to specific causes is less well documented [9]. The efficacy and effectiveness of interventions for child survival could be affected by the child's characteristics, such as clinical. In addition, centers that provide care for malnourished children may also present some factors that could influence the mortality rate. The objective for the present study was to determine the factors associated with the mortality of children with SAM in the Center for Recovery and Nutritional Education (CREN) of CHUYO.

\section{METHODS}

\section{Participants}

This was a case-control study designed to determine the factors associated with the mortality of children with severe acute malnutrition from 31 January 2009 to 31 January 2013 at the CREN of the Pediatrics Department of the CHU-YO in Ouagadougou. Ouagadougou is the capital city of Burkina Faso and the CHU-YO is the biggest teaching hospital of the country. The CREN is in charge of the treatment of children presenting SAM with or without complications. Children generally treated in this center are from Ouagadougou and its surroundings.

The population was made up of 433 children aged, 0 to 59 months, dead or recovered, of both sexes who suffered from SAM with or without complications. The inclusion criteria for participants in the study were: child aged 0-59 months, admitted to the CREN and that had bipedal edema, or weight-for-height z-score $(\mathrm{WHZ})<-3$ $\mathrm{SD}$ of the median reference (for children 0-59 months), or the mid-upper arm circumference (MUAC) $<110 \mathrm{~mm}$ (only for those aged 6-59 months) [10]. Children that were admitted to the CREN but later transferred or dropped out were excluded from this study. The control group was composed of all children included in the study that recovered after being treated for SAM; and the case group consisted of all the children included in the study who died while being under treatment for SAM. The total samples consisted of 361 controls and 72 cases.

\section{Instrumentation and Procedure}

At the admission to the CREN, weight and height were measured for all children and MUAC was assessed for those aged 6-59 months. A clinical assessment was performed to determine the presence of associated clinical signs and complications (infections and other complications) at the entry. The following biological testing was performed on all the children: HIV serology, hemoglobin concentration, protidemia, serum potassium, serum sodium, creatinine and blood sugar. Children's socioeconomic characteristics were collected including age and sex of children; their health history (immunization status, number of prenatal consultations and feeding information from 0-6 months) were also recorded.

\section{Data Analysis}

Data were entered and analyzed using SPSS version 17.0. The anthropometrics indices height-forage z-score (HAZ), weight-for-height z-score (WHZ) and weight-for-age $z$-score (WAZ) were calculated using the WHO software Anthro. 2010. For the evaluation of nutritional status with MUAC, acute malnutrition was considered severe when the MUAC was lower than $110 \mathrm{~mm}$ (for children aged 6-59 months), according to the national protocol in the place at the time of this study [10]. The distribution of quantitative variables were checked using the noparametric test Shapiro-Wilk, and distribution was assumed to be normal when $p$-value was better than 0.05. Descriptive analyses were performed. This analysis of the mortality determinants was performed in two steps. Firstly, univariate analyses were conducted to determine the relevant variables using Student $T$ test or Mann-Whitney test for continuous variables, and Chi square and Fisher Exact tests for categorical variables with a $p$-value $<0.05$ considered as significant. In the second step, a multinomial logistic regression was used to examine the weight of the different relevant variables determined during the first step, adjusting for each other in each category of determinants (clinical symptoms, infections, other complications, biochemical and anthropometric parameters). A backward regression walk through was undertaken; and seizure tests $(p<0.05)$ and suppression $(p>0.10)$ were based on the likelihood ratio. In addition to these analyses, a correlation matrix was used to examine the correlations between the various predictors. Where variables were highly correlated, it was the preferred choice of the researchers to remove somewhat we considered as redundant variables. In the various inferential analyses, the difference was significant when "p" $\leq 0.05$ 


\section{RESULTS}

\section{Participants' Baseline Socio-Economic Health Characteristics}

The children's mean age at the admission to the CREN was $16.9 \pm 9.0$ months. The age group 6-23 months was the most populated group was (77.6\%); the sex ratio was 1.20. However, there was no association between sex and mortality. Table 1 present the distribution of children by age and stratified by sex.

For the group of 128 children whom feeding practices information was available, $68.8 \%$ of them were exclusively breastfed until the age of 6 months, $21.9 \%$ received mixed feeding and $9.4 \%(n=12)$ were fed breast milk substitutes. Among the 294 children whom immunization status was informed, $76.5 \%$ of them correctly received their vaccines as scheduled by the national extended program of immunization. The number of antenatal visits was informed for 267 children; $\geq 4$ antenatal visits were reported only for $31.5 \%$ of them (Table 1 ).

For the age of the children when they were admitted to the center is associated with mortality and younger children were more at odds of death (Table 1).

\section{Clinical Signs at the Admission to the CREN}

The prevalence of clinical signs is presented in Table 2. The most encountered clinical signs at children's admission to the CREN were diarrhea $(41.1 \%)$, cough $(25.6 \%)$, edema $(21.9 \%)$ and vomiting (21.7\%). Anorexia (19.2\%) and hepatomegaly (19.2\%) were also prevalent. Besides that, in the multivariate analyses, only diarrhea $[\mathrm{OR}=4.6(95 \% \mathrm{Cl} 2.6-8.2)]$,

Table 1: Distribution by Age and Stratified by Gender and Socio-Sanitary Characteristics

\begin{tabular}{|c|c|c|c|c|c|}
\hline \multirow[t]{2}{*}{$\begin{array}{l}\text { Groups of Age } \\
\text { (Months) }\end{array}$} & \multicolumn{2}{|c|}{ Combined Groups } & \multicolumn{2}{|c|}{$\begin{array}{c}\text { Sex } \\
\text { Effective }\end{array}$} & \multirow[t]{2}{*}{ Sex Ratio } \\
\hline & Effective & Percentage & Male & Female & \\
\hline $0-5$ & 15 & $3.5 \%$ & 9 & 6 & 1.5 \\
\hline $6-11$ & 119 & $27.5 \%$ & 64 & 55 & 1.2 \\
\hline $12-23$ & 202 & $46.6 \%$ & 110 & 92 & 1.2 \\
\hline 24-35 & 78 & $18.0 \%$ & 46 & 32 & 1.4 \\
\hline$\geq 36$ & 19 & $4.4 \%$ & 8 & 11 & 0.7 \\
\hline Total population & 433 & $100 \%$ & 237 & 196 & 1.2 \\
\hline Variables & \multicolumn{2}{|c|}{ Estimated Coefficients } & \multicolumn{2}{|c|}{ P-Value } & OR $(95 \% \mathrm{CI})$ \\
\hline Constant & \multicolumn{2}{|c|}{9.294} & \multicolumn{2}{|c|}{$\mathrm{p}<0.001$} & \\
\hline Ages & \multicolumn{2}{|c|}{0.063} & \multicolumn{2}{|c|}{$\mathrm{p}<0.001$} & $\begin{array}{c}1.1 \\
{[1.0 ; 1.1]}\end{array}$ \\
\hline \multicolumn{6}{|c|}{ Socio-Sanitary Characteristics } \\
\hline \multicolumn{2}{|c|}{$\begin{array}{l}\text { Food practices from } 0 \text { to } 6 \text { months } \\
\qquad(n=128)\end{array}$} & \multicolumn{2}{|c|}{ Effective } & \multicolumn{2}{|c|}{ Percentages } \\
\hline \multicolumn{2}{|c|}{ Breastfeeding } & \multicolumn{2}{|c|}{88} & \multicolumn{2}{|c|}{$68.8 \%$} \\
\hline \multicolumn{2}{|c|}{ Mixed feeding } & \multicolumn{2}{|c|}{28} & \multicolumn{2}{|c|}{$21.9 \%$} \\
\hline \multicolumn{2}{|c|}{ Breastmilk Substitutes } & \multicolumn{2}{|c|}{12} & \multicolumn{2}{|c|}{$9.4 \%$} \\
\hline \multicolumn{2}{|c|}{$\begin{array}{l}\text { Immunization schedule } \\
\qquad(\mathrm{n}=294)\end{array}$} & \multicolumn{2}{|c|}{ Effective } & \multicolumn{2}{|c|}{ Percentages } \\
\hline \multicolumn{2}{|c|}{ Schedule up date } & \multicolumn{2}{|c|}{225} & \multicolumn{2}{|c|}{$76.5 \%$} \\
\hline \multicolumn{2}{|c|}{ Calendar of date } & \multicolumn{2}{|c|}{69} & \multicolumn{2}{|c|}{$23.5 \%$} \\
\hline \multicolumn{2}{|c|}{$\begin{array}{l}\text { Number of prenatal consultations } \\
\qquad(n=267)\end{array}$} & \multicolumn{2}{|c|}{ Effective } & \multicolumn{2}{|c|}{ Percentages } \\
\hline & & & & & \\
\hline & & & & & \\
\hline
\end{tabular}

n: Number Observed. 
Table 2: Prevalence of Clinical Findings at Admission and their Association with Mortality

\begin{tabular}{|c|c|c|c|c|c|}
\hline Clinical Signs & $\begin{array}{l}\text { Control } \\
(n=361)\end{array}$ & $\begin{array}{c}\text { Case } \\
(n=72)\end{array}$ & OR $(95 \% \mathrm{Cl})$ & P-Value & $\begin{array}{l}\text { Prevalence in the } \\
\text { Total Population }\end{array}$ \\
\hline Diarrhea & 127 & 51 & $\begin{array}{c}4.5 \\
{[2.6 ; 7.8]}\end{array}$ & $p<0.001$ & $41.1 \%$ \\
\hline Anorexia & 58 & 25 & $\begin{array}{c}2.8 \\
{[1.6 ; 4.9]}\end{array}$ & $p<0.001$ & $19.2 \%$ \\
\hline Edema & 71 & 24 & $\begin{array}{c}2.0 \\
{[1.2 ; 3.5]}\end{array}$ & 0.016 & $21.9 \%$ \\
\hline Hepatomegaly & 57 & 26 & $\begin{array}{c}3.0 \\
{[1.7 ; 5.3]}\end{array}$ & $p<0.001$ & $19.2 \%$ \\
\hline Cough & 86 & 25 & $\begin{array}{c}1.7 \\
{[0.9 ; 2.9]}\end{array}$ & 0.074 & $25.6 \%$ \\
\hline Vomiting & 72 & 22 & $\begin{array}{c}1.8 \\
{[1.0 ; 3.1]}\end{array}$ & 0.060 & $21.7 \%$ \\
\hline $\begin{array}{c}\text { Variables } \\
\text { and constant }\end{array}$ & $\begin{array}{l}\text { Estimated } \\
\text { coefficients }\end{array}$ & \multicolumn{2}{|c|}{ P-Value } & \multicolumn{2}{|c|}{ OR $(95 \% \mathrm{Cl})$} \\
\hline Constant & -3.072 & \multicolumn{2}{|c|}{$p<0.001$} & & \\
\hline Diarrhea & 1.531 & \multicolumn{2}{|c|}{$\mathrm{p}<0.001$} & \multicolumn{2}{|c|}{$\begin{array}{c}4.6 \\
{[2.6 ; 8.2]}\end{array}$} \\
\hline Anorexia & 1.003 & \multicolumn{2}{|c|}{0.001} & \multicolumn{2}{|c|}{$\begin{array}{c}2.7 \\
{[1.5 ; 5.0]}\end{array}$} \\
\hline Hepatomegaly & 0.970 & \multicolumn{2}{|c|}{0.002} & \multicolumn{2}{|c|}{$\begin{array}{c}2.6 \\
{[1.4 ; 4.8]}\end{array}$} \\
\hline Edema & 0.583 & \multicolumn{2}{|c|}{0.059} & \multicolumn{2}{|c|}{$\begin{array}{c}1.8 \\
{[0.9 ; 3.3]}\end{array}$} \\
\hline
\end{tabular}

n: Number Observed.

anorexia [OR $=2.7(95 \% \mathrm{Cl} 1.4-5.0)]$ and hepatomegaly $[\mathrm{OR}=2.6(95 \% \mathrm{Cl} 1.4-4.8)]$ were still associated with mortality.

The infections associated with severe acute malnutrition at children's admission were malaria ( $40.4 \%$ of cases), digestive infections ( $26.6 \%$ of cases), respiratory infections (13.9\% of cases), HIV/AIDS (13.4\% of cases) and fungal infections $(13.4 \%$ of cases).

In the multivariate analyses, the presence of the following infections was associated with an increased odds of dying from severe acute malnutrition (Table 3 ) $\mathrm{HIV} / \mathrm{AIDS} \quad[\mathrm{OR}=10.9 \quad(95 \% \mathrm{Cl}$ 5.6-21.5)], gastrointestinal infections $[\mathrm{OR}=5.1(95 \% \mathrm{Cl} 2.8-9.4)$ ].

Other complications present at children's admission to the CREN were severe dehydration (18.0\%), severe anemia $(15.9 \%)$, skin lesions (12.2\%), and heart failure (6.9\%). These complications were associated with death in SAM $(p<0.05)$. All these complications were associated with increased odds of death with SAM: severe dehydration [OR $=16.4(95 \% \mathrm{Cl} 8.0-33.5)]$, skin lesions [OR $=14.3(6.4-31.9)$ ], heart failure [OR $=6.8$ $(95 \% \mathrm{Cl} 2.5-19.0)]$ and severe anemia $[\mathrm{OR}=$ 3.2(95\% Cl 1.4-7.1)] (Table 4).

\section{Anthropometrics Factors}

At the admission to the CREN, 127 children were extremely malnourished (z-score $<-4 \mathrm{SD}$ for $\mathrm{WHZ}$, $H A Z$ and WAZ). Anthropometric indices (WHZ, HAZ, and $W A Z$ ) and MUAC were negatively associated with the mortality of children with SAM when data of extremely malnourished were included in the analysis; but when these children were excluded from the samples, WHZ and WAZ were not associated anymore (Table 5). The most crucial factors among anthropometric variables were the MUAC of children at the point of entry at the center (Table 5). Additionally, mortality rate gradually increased with poor nutritional status. 
Table 3: Prevalence of Infections and their Association with Mortality

\begin{tabular}{|c|c|c|c|c|c|}
\hline Infections & $\begin{array}{l}\text { Control } \\
(n=361)\end{array}$ & $\begin{array}{l}\text { Case } \\
(n=72)\end{array}$ & OR $(95 \% \mathrm{Cl})$ & P-Value & $\begin{array}{l}\text { Prevalence in the } \\
\text { Total Population }\end{array}$ \\
\hline Digestive infections & 73 & 42 & $\begin{array}{c}5.5 \\
{[3.2 ; 9.4]}\end{array}$ & $p<0.001$ & $26.5 \%$ \\
\hline Mycoses & 32 & 13 & $\begin{array}{c}2.3 \\
{[1.1 ; 4.6]}\end{array}$ & 0.034 & $10.39 \%$ \\
\hline AIDS pediatric & 24 & 34 & $\begin{array}{c}12,6 \\
{[6.7 ; 23,4]}\end{array}$ & $\mathrm{p}<0.001$ & $13.39 \%$ \\
\hline Malaria & 137 & 38 & $\begin{array}{c}1.8 \\
{[1.1 ; 3.0]}\end{array}$ & 0.025 & $40.42 \%$ \\
\hline $\begin{array}{l}\text { Respiratory } \\
\text { Infections }\end{array}$ & 44 & 16 & $\begin{array}{c}2.0 \\
{[1.1 ; 3.9]}\end{array}$ & 0.038 & $13.86 \%$ \\
\hline $\begin{array}{c}\text { Variables } \\
\text { and Constant }\end{array}$ & $\begin{array}{l}\text { Estimated } \\
\text { Coefficient }\end{array}$ & \multicolumn{2}{|c|}{ P-Value } & \multicolumn{2}{|c|}{ OR (95\% Cl) } \\
\hline Constant & -3.186 & \multicolumn{2}{|c|}{$p<0.001$} & & \\
\hline AIDS pediatric & 2.393 & \multicolumn{2}{|c|}{$p<0.001$} & \multicolumn{2}{|c|}{$\begin{array}{c}10.9 \\
{[5.6 ; 21.5]}\end{array}$} \\
\hline Digestive infections & 1.632 & \multicolumn{2}{|c|}{$p<0.001$} & \multicolumn{2}{|c|}{$\begin{array}{c}5.1 \\
{[2.8 ; 9.4]}\end{array}$} \\
\hline Mycoses & 0.875 & \multicolumn{2}{|c|}{0.046} & \multicolumn{2}{|c|}{$\begin{array}{c}2.4 \\
{[1.0 ; 5.7]}\end{array}$} \\
\hline Malaria & 0.670 & \multicolumn{2}{|c|}{0.031} & \multicolumn{2}{|c|}{$\begin{array}{c}1.9 \\
{[1.1 ; 3.6]}\end{array}$} \\
\hline
\end{tabular}

$\mathrm{n}$ : Number Observed.

Table 4: Prevalence of other Complications of SAM and their Association with Mortality

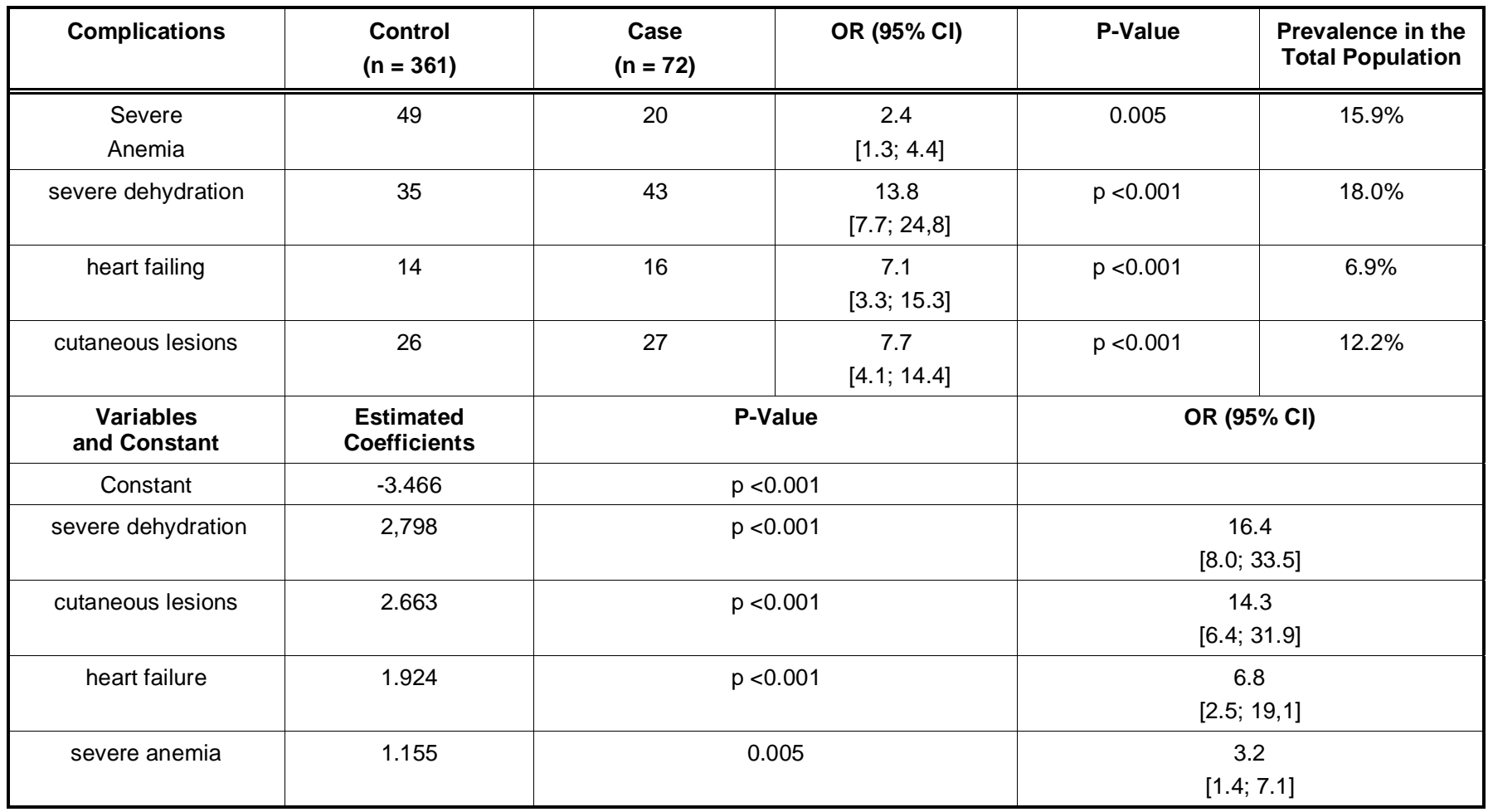

$\mathrm{N}$ : Number Observed. 
Table 5: Anthropometric z-Scores and Biochemical Factors and their Association with Mortality

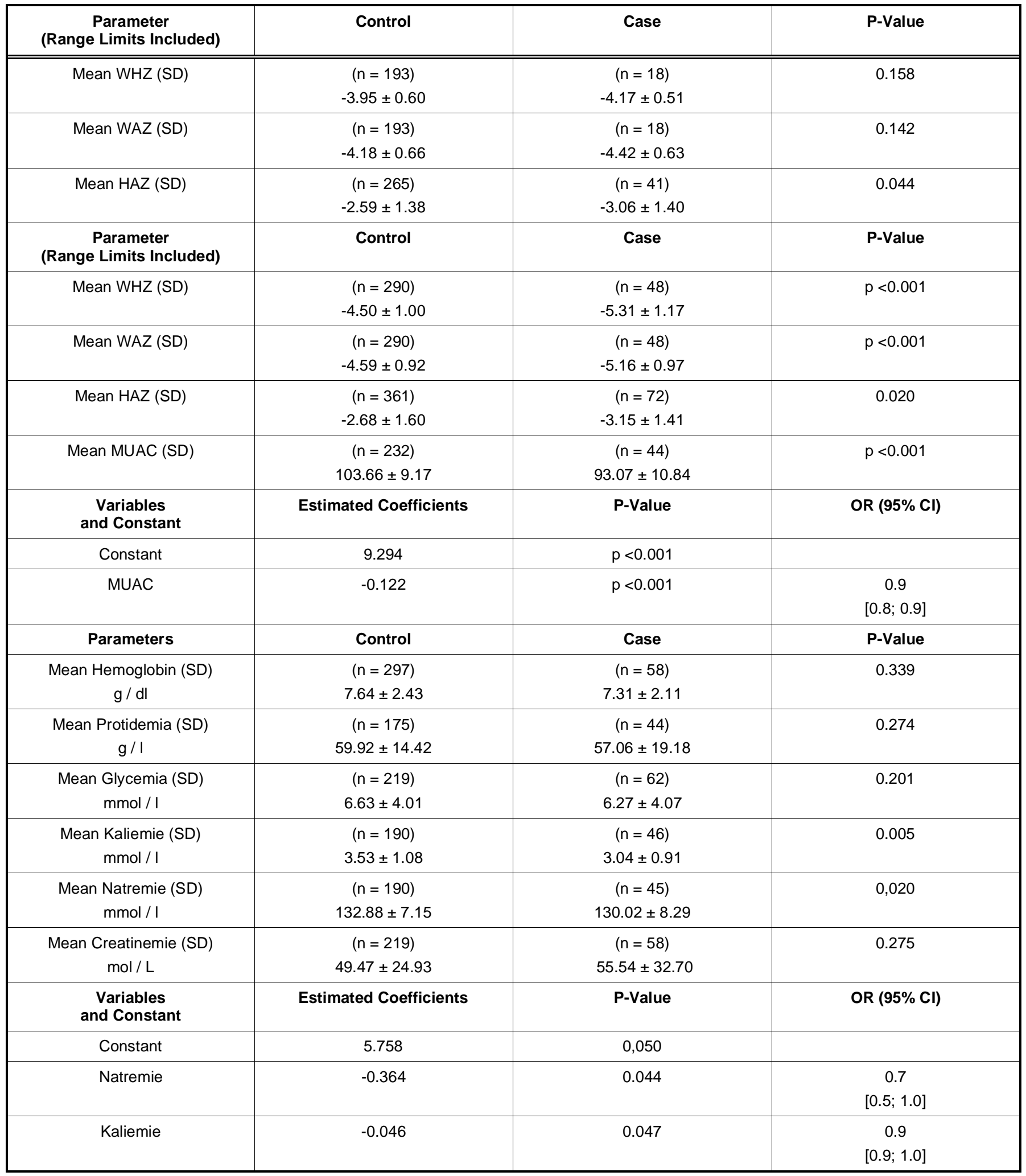

SD: Standard Deviation; n: Number Observed.

\section{Biochemical Factors}

Mean hemoglobin concentration was $7.58 \pm 2.38$ $\mathrm{g} / \mathrm{dL}(\mathrm{n}=355)$ and the mean glycemia $6.55 \pm 4.02$ $\mathrm{mmol} / \mathrm{L}(\mathrm{n}=281)$. The mean protidemia, creatinine, serum sodium and potassium concentrations were 59.4 $\pm 15.5 \mathrm{~g} / \mathrm{L}(\mathrm{n}=219), 50.7 \pm 26.8 \mu \mathrm{mol} / \mathrm{L}(\mathrm{n}=277), 132.3$ 
$\pm 7.4 \mathrm{mmol} / \mathrm{L}(\mathrm{n}=235)$ and $3.4 \pm 1.1 \mathrm{mmol} / \mathrm{L}(\mathrm{n}=236) . \mathrm{ln}$ univariate analyses, only the associations between hypokalemia, hyponatremia and mortality of children with SAM were significant. These two biochemical indicators were still significantly associated with death of children with SAM in the multivariate analyses (Table 5); the more pronounced the hypokalemia, the higher the odds of mortality was. The more pronounced the hyponatremia, the lower the odds of mortality was.

\section{DISCUSSION}

The results reveal poor feeding practices, health and social care. Indeed, $21.9 \%$ of children received mixed feeding during their first six months of life. In addition, $77.6 \%$ of children were in the age group 6-23 months which corresponds to weaning and complementary feeding period considered by many authors as a critical age bracket for the development of malnutrition [12, 14]. Moreover, about one fourth $(23.5 \%)$ children did not update their vaccination records which may be due to non-compliance. These results are similar to those reported by the Demographic and Health Survey (DHS) in 2010, which showed that $19.8 \%$ and $19.5 \%$ of children aged $12-23$ months in Ouagadougou and the central region of Burkina, respectively, have not been up to date with their vaccinations [13]. Furthermore, the WHO guidelines recommend at least four antenatal visits at regular intervals throughout pregnancy but in the present study this recommendation was met for only $31.5 \%$ of the participants. This rate is far lower compared to those found by the DHS in 2010: $99 \%$ and $98.5 \%$ for the central region of Burkina and the city of Ouagadougou, respectively. Associated infectious diseases are known to aggravate malnutrition [13].

In this study, diarrhea, cough and vomiting were the three most prevalent clinical signs associated with SAM at the admission $(41.1 \%, 25.6 \%$, and $21.7 \%$, respectively). The prevalence of anorexia, hepatomegaly and edema was also relatively high (Table 2). This combination of diseases could increase the risk of death in children with an immune system already weakened by malnutrition. Indeed, we found that diarrhea was a critical determining factor of mortality in children with SAM. The presence of diarrhea at the admission was associated with four folds odds of dying with SAM (Table 2). Hospital studies have previously highlighted a similar relationship between malnutrition and increased risk of death from diarrhea [8, 12-14]. Similar to our finding, a case-control study in Bangladesh also reported high rate of death from dysentery in children with SAM [OR $=8.995 \% \mathrm{Cl} 1.9-45.7$ ] [9]. Children who died from diarrhea, despite good management of dehydration were observed to be usually severely malnourished [8]. Clinical signs, such as anorexia and hepatomegaly were also associated with the mortality as related to infections, which are known in children with SAM as factors increasing the risk of death. Clinical signs, indicative of infections and malaria particularly, were the ones observed in this study.

In addition, digestive infections, fungal infections and AIDS, main causes of diarrhea, were also observed (Table 3). Several authors have reported the presence of these infections in malnourished children [8, 9]. In our study, HIV/AIDS and digestive infections were the best predictors of mortality of children with SAM. The odds of death were 10 times higher in severely malnourished children with HIV/AIDS compared to their counterparts without HIV/AIDS; this may due to the combinatory consequence of HIV/AIDS and malnutrition that are both immunosuppressive syndromes. In addition, it should be noted that some children are admitted to the CREN at a very advanced stage of HIV and yet are not receiving antiretroviral therapy. Most of them die before or shortly after the initiation of antiretroviral treatment. The second important group of infections associated with higher odds of death was digestive infections.

In general, infections resulting in complications are the leading immediate causes of death and disability in children worldwide [9]. The disease burden associated with these diseases is particularly acute in developing countries [9]. Additionally, these diseases are responsible for other medical and/or metabolic complications that hinder the management of malnutrition (Table 4). In this case, severe dehydration was found in $18.0 \%$ of cases and could have resulted from diarrhea and vomiting, which were prevalent clinical signs reported at the admission of children; skin lesions (12.2\%) may result from severe acute malnutrition, edema and other skin conditions; severe anemia $(15.9 \%)$ may be the consequence of malaria (especially anemic form of severe malaria) or other infections associated with an insufficient dietary intake. Another type of complications associated with SAM and observed in this study was heart failure $(6.9 \%)$ which could result from deep or myocardial overload anemia $[10,15]$. The main complication associated with death in SAM was severe dehydration; the odds of death was 16 times higher in severely dehydrated children with SAM (Table 4). 
Diarrheal diseases, with dehydration as a subsequent complication, are known to be the major cause of child death in developing countries [14]. Skin lesions were associated with the second highest odds of death in SAM; ulcerations and exudative lesions are complications that increase the risk of mortality. These lesions are most often accompanied by secondary infections. Other complications associated with an increased odds of death were heart failure ( 6 folds increase) and severe anemia (3 folds increase). In case of severe anemia, heart failure can lead to the patient' death [15]. In general, complications, reported in the literature to be strongly associated with mortality $[8,15]$.

Among the anthropometric indicators, the MUAC at the admission was the most critical determinant of mortality in children with SAM (Table 5). The lower the MUAC, the higher the odds of dying with SAM was. Based on that, MUAC would be the best predictor of mortality compared to other anthropometric indices. The MUAC is the index that best identifies children at high risk of death [16]. A previous study similarly reported that the risk of mortality increased gradually with poor nutritional status in children with acute malnutrition $[12,16,17]$.

Moreover the same study also showed that younger age was associated with higher odds of death of children with acute malnutrition. Our result regarding the association of age with odds of death is consistent with the findings of Traore in Burkina showing that age was a determining factor in the mortality of malnourished children [18].

The mean hemoglobin concentration of the children was low explaining the prevalence of anemia found in the present study. The 2010 Burkina Faso DHS showed that $88 \%$ of children under five years were suffering from anemia nationwide [13]. The mean serum potassium level was slightly below normal limits (3.5-5.2 $\mathrm{mmol} / \mathrm{L})$ and may be the consequence of losses due to diarrhea and/or vomiting. We found that hypokalemia and hyponatremia were associated with the risk of death in children with SAM. The deeper the hypokalemia, the higher the odds of death was; and the deeper the hyponatremia, the lower the odds of death was (Table 5). Generally, increased losses of water and electrolytes by the liquid stools, and subsequent dehydration are factors that increase the mortality in malnutrition [14].

This study has limitations. The first one is related to the case-control design. Children's clinical and therapeutic records were incomplete leading to a reduction in sample sizes for the different variables of interest. This could have biased our findings.

\section{CONCLUSION}

The study has highlighted the relationship between mortality and a number of factors in the SAM. The results indicate that odds of death is different as function of factors of the same category (clinical signs, infection, complications, anthropometric factors and biochemical factors), and also show the most predictive factors of mortality of children with SAM. For clinical signs, determinants of mortality were diarrhea, anorexia and hepatomegaly. For infections, determinants of mortality were pediatric AIDS and digestive infections. For other complications, determinants of mortality were severe dehydration, skin lesions, heart failure and severe anemia. The deeper the hypokalemia, the higher the odds of death was; and the deeper the hyponatremia, the lower the odds of death was. In addition, the lower the MUAC, the higher the odds of dying with SAM was. Some of the factors that were not found to be associated with death in this study could still contribute to the death of children with SAM. Longitudinal studies are needed to better clarify the relationship between the studied factors and mortality of children with SAM. The identification of these factors and its effective use in the care of severely malnourished children might help to reduce mortality due to malnutrition.

The results of this study raise recommendations. Indeed, great importance should be attached to measures MUAC would be the best predictor of mortality among the anthropometric indices. An update dashboards in health centers needs to be done; which could have a favorable impact in reducing mortality due to malnutrition. Additionally, since the admission of a malnourished child in a health center, laboratory tests should be done to better address certain complications. This would then require assistance in the form of government subsidy or its technical and financial partners. In addition, the strengthening of HIV testing must be done to help reduce mortality.

\section{ACKNOWLEDGEMENTS}

Authors want to acknowledge Dr. Francis Zotor from University of Health \& Allied Sciences and Dr. Jerome Some from Institut de Recherche en Sciences de la Santé (IRRS, Bobo-Dioulasso) for editing this paper and contribute to improve its quality. Finally, the 
authors thank greatly the project ISP-IPICS from University of Uppsala (Sweden) for its financial support to publish paper.

\section{REFERENCES}

[1] World Health Organization. (Page consultée le 02 février 2015). Child Malnutrition Database, [en ligne]. http://www.who.int/nutgrowthdb/estimates2012/en/.

[2] Black RE, Allen LH, Bhutta ZA, et al. Maternal and Child Undernutrition Study Group. Maternal and child undernutrition: global and regional exposures and health consequences. Lancet 2008; 371: 243-60. http://dx.doi.org/10.1016/S0140-6736(07)61690-0

[3] Sib O, Ouedraogo T, Degueurse $\mathrm{S}$, et al. Evaluation approfondie de la situation alimentaire des ménages dans 170 communes déclarées à risque au Burkina Faso. Rome: PAM 2012.

[4] Direction de la Nutrition. Rapport enquête nutritionnelle nationale de 2012. Ouagadougou: Direction de la nutrition 2012.

[5] Direction générale de l'information et des statistiques sanitaires. Annuaire statistique 2011 du Burkina Faso. Ouagadougou: DGISS 2012.

[6] Koum DK, Dissongo J, Penda $\mathrm{Cl}$, et al. Severe acute malnutrition among children 6 to 59 months hospitalized in Douala Cameroon. Acta Theol 2013; 3(2).

[7] Bete FH. Audit de la prise en charge des enfants malnutris aigus sévères admis au centre nutritionnel thérapeutique (CNT) de l'hôpital évangélique de Bembèrèkè au cours du second semestre de l'année 2010. [Mémoire de master 2 en santé publique et environnement]. Nancy: Université Henri Poincaré 2011.

[8] Ashworth A, Khanum S, Jackson A, Schofield C. Directives pour le traitement hospitalier des enfants sévèrement malnutris. Genève: OMS 2004.
[9] Rice AL, Sacco L, Hyder A, Black RE. La malnutrition: cause sous-jacente des décès de l'enfant par maladies infectieuses dans les pays en développement. B World Health Organ 2001; 78: 1207-21.

[10] Direction de la Nutrition. Protocole national de prise en charge de la malnutrition aiguë. Ouagadougou: Direction de la nutrition 2007.

[11] Tiendrebeogo RSS. Evaluation de la prise en charge de la malnutrition aiguë sévère dans le service de pédiatrie du CHU-YO. [Mémoire de Maîtrise en sciences et techniques] Ouagadougou: Université de Ouagadougou 2009.

[12] Sondé I. Analyse de la prise en charge d'enfants en malnutrition au centre de récupération nutritionnelle de Tenghin. [Mémoire de Master en santé publique]. Liège : Université de Liège 2009.

[13] Institut National de la Statistique et de la Démographie, ICF International. Enquête Démographique et de Santé et à Indicateurs multiples du Burkina Faso 2010. USA: INSD, ICF International 2011

[14] Organisation Mondiale de la Santé. Le traitement de la diarrhée in manuel à l'usage des médecins et autres personnels de santé qualifiés. Genève: OMS 2006.

[15] Golden M, Grellety Y. Protocol integrated management of acute malnutrition. Michael H. Golden and Dr. Yvonne Grellety 1992-2011.

[16] Organisation mondiale de la santé. Normes de Croissance OMS et Identification de la malnutrition chez l'enfant. Genève: OMS 2010

[17] Norman K, Pichard C, Lochs H, Pirlich M. Prognostic impact of disease-related malnutrition. Clin Nutr 2008; 27: 5-15. http://dx.doi.org/10.1016/j.clnu.2007.10.007

[18] Traoré WA. Facteurs déterminants de la mortalité dans les centres: cas des centres OASIS à Koudougou et de Kayero à Léo au Burkina Faso. [Mémoire de maitrise en sciences et techniques]. Ouagadougou: Université de Ouagadougou 2006.

http://dx.doi.org/10.6000/1929-4247.2016.05.01.1

(C) 2016 Zoubga et al.; Licensee Lifescience Global.

This is an open access article licensed under the terms of the Creative Commons Attribution Non-Commercial License (http://creativecommons.org/licenses/by-nc/3.0/) which permits unrestricted, non-commercial use, distribution and reproduction in any medium, provided the work is properly cited. 